\title{
CCAAT/enhancer binding protein activates the promoter of the serum albumin gene in cultured hepatoma cells
}

\author{
Alan D. Friedman, William H. Landschulz, and Steven L. McKnight \\ Howard Hughes Research Laboratories, Carnegie Institution of Washington, Department of Embryology, Baltimore, Maryland \\ 21210 USA
}

\begin{abstract}
An expression vector capable of encoding full-length CCAAT/enhancer-binding protein (C/EBP) has been constructed and tested in transient transfection assays for its capacity to activate transcription from the promoter of the serum albumin gene. When tested in cultured hepatoma cells, the C/EBP expression vector achieved potent trans-activation of the albumin promoter. Less substantial activation was observed when the same experiment was conducted using cultured mouse fibroblasts. Expression vectors that encoded defective forms of C/EBP failed to activate the albumin promoter. Moreover, mutated variants of the albumin promoter that lack the C/EBP-binding site failed to be trans-activated. The data are consistent with the interpretation that $\mathrm{C} / \mathrm{EBP}$ is a bona fide transcription factor. During the course of these experiments it was noted also that C/EBP is more than an order of magnitude less concentrated in cultured hepatoma cells than it is in adult liver cells. Given these findings, we speculate that C/EBP may play a general role in establishing and maintaining the differentiated, nonproliferative state.
\end{abstract}

[Key Words: C/EBP; albumin; HepG2 cells; cell differentiation]

Received May 18, 1989; accepted July 5, 1989.

CCAAT/enhancer binding protein $|\mathrm{C} / \mathrm{EBP}\rangle$ is a sequence-specific, DNA-binding protein purified initially from rat liver nuclei (Graves et al. 1986; Johnson et al. 1987). As assayed in vitro, C/EBP is capable of selective interaction with cis-regulatory DNA sequences known to mediate positive control of messenger RNA (mRNA) synthesis. Binding sites for C/EBP include 'CCAAT boxes' and 'enhancer core homologies,' leading to the terminology $\mathrm{C} / \mathrm{EBP}$. Given the proclivity of $\mathrm{C} / \mathrm{EBP}$ to bind to positively acting cis- regulatory DNA sequences, it has been anticipated that C/EBP might constitute a transcriptional regulatory protein.

The gene that encodes C/EBP has been cloned and sequenced (Landschulz et al. 1988a). Inspection of the amino acid sequence of C/EBP revealed primary sequence similarity to the products of several proto-oncogenes (Landschulz et al. 1988a), leading to the prediction of a b:partite DNA-binding domain common to a newly defined class of genetic regulatory proteins (Landschulz et al. 1988b). Evidence supporting the bipartite nature of the C/EBP DNA-binding domain has been presented recently (Landschulz et al. 1989).

Expression of C/EBP is tissue restricted (Birkenmeier et al. 1989/. In the mouse, C/EBP is found most abundantly in fat, liver, and lung tissue. Beyond being limited in tissue distribution, $\mathrm{C} / \mathrm{EBP}$ is restricted further to terminally differentiated cells (Birkenmeier et al. 1989). In liver, it is only found in fully differentiated hepatic (parenchymal) cells. Likewise, cultured fat cells only ex- press $C / E B P$ at the point of conversion of proliferative adipoblasts into fully differentiated adipocytes.

Observations revealing the tissue and cell-type specificity of $\mathrm{C} / \mathrm{EBP}$ expression contradict the notion that $\mathrm{C} / \mathrm{EBP}$ is a generic transcription factor, required for the expression of many or all mRNA coding genes. The protein, instead, appears better suited for the activation or repression of genes that are regulated as a function of terminal cell differentiation. Perhaps C/EBP activates certain genes that encode 'luxury' proteins-proteins that determine the specialized phenotypes of differentiated cells. Observations consistent with this notion have emerged from recent studies of genes that are expressed in differentiated liver cells. Darnell and colleagues have shown that C/EBP is capable of specific interaction with cis-regulatory DNA sequences associated with three genes that are expressed selectively in livertransthyretin, $\alpha-1$-antitrypsin, and albumin /Costa et al. 1988). Evidence that the in vitro binding of C/EBP to liver-specific genes may be relevant physiologically has emerged from detailed studies on the rat serum albumin gene. The groups of both Schibler and Yaniv have shown that active use of the promoter of the albumin gene, whether assayed in vivo or in vitro, depends on the integrity of a cis-regulatory element that binds C/EBP (Gorski et al. 1986; Cereghini et al. 1987; Heard et al. 1987; Lichtsteiner et al. 1987; Maire et al. 1989).

Despite many suggestive indications that $\mathrm{C} / \mathrm{EBP}$ might be capable of acting as a transcriptional regulatory 
protein, we are unaware of any direct evidence supporting this notion. To conduct an explicit test of the capacity of C/EBP to regulate transcription, we carried out transient transfection experiments using an expression vector that allows C/EBP to be produced in cells that otherwise contain little or no C/EBP. We show that $\mathrm{C} / \mathrm{EBP}$ is a potent activator of transcription from the serum albumin promoter in cultured hepatoma cells, and a weak activator of the same promoter in cultured fibroblast cells. We show further that the capacity of $\mathrm{C} / \mathrm{EBP}$ to function as an activator of albumin transcription is dependent both on its ability to bind DNA, and on the integrity of its binding site within the albumin promoter.

\section{Results}

\section{Cultured, hepatoma-derived cells contain significantly} less C/EBP than normal hepatocytes

A liver-derived cell line lacking C/EBP would constitute an ideal setting in which to investigate the ability of the protein to regulate albumin gene expression. Evidence has been presented already that suggests that HepG2 cells, derived from a human hepatoma, may differ from liver in C/EBP content (Babiss et al. 1987). To investigate this observation in more detail, Western blots were prepared from protein samples derived from various cell and tissue types, and stained with a mixture of two C/EBP-specific antibodies (Landschulz et al. 1988a; Birkenmeier et al. 1989|.

As presented in Figure 1, individual lanes of a sodium dodecyl sulfate (SDS)-polyacrylamide electrophoresis gel were loaded with equivalent amounts of extract derived from either rat liver tissue, HepG2 cells (Aden et al. 1979), thymidine kinase (tk)-deficient mouse L cells (Kit et al. 1963), or H4IIEC3 rat hepatoma cells (Reuber 1961). Consistent with earlier studies (Landschulz et al. 1988a), substantial levels of C/EBP were observed in the extract derived from rat liver. Relative to the $25-\mathrm{ng}$ C/EBP standard (purified after overexpression of the protein in bacterial cells), extract derived from $1.5 \times 10^{6}$ rat liver nuclei contained roughly $10 \mathrm{ng}$ of intact C/EBP. This mass of the $42-\mathrm{kD}$ C/EBP polypeptide corresponds to roughly $1.5 \times 10^{11}$ polypeptide chains, or about 100,000 molecules per nucleus. There are several reasons to suspect that this number represents an underestimate of the actual concentration of C/EBP in parenchymal cell nuclei. First, not all of the nuclei isolated from rat liver are derived from parenchymal cells, which is the exclusive cell type that expresses C/EBP (Birkenmeier et al. 1989). Second, C/EBP might be lost to either proteolysis or leakage during nuclear isolation. Indeed, lower-molecular-weight forms of the protein are known to be generated during purification (Landschulz et al. 1988a).

The two hepatoma-derived cell lines appeared to exhibit substantially lower levels of C/EBP than liver-derived hepatocytes. Judging from the intensity of the radioactive bands shown in the Western blot of Figure 1, we estimate that both cultured hepatoma-derived cell

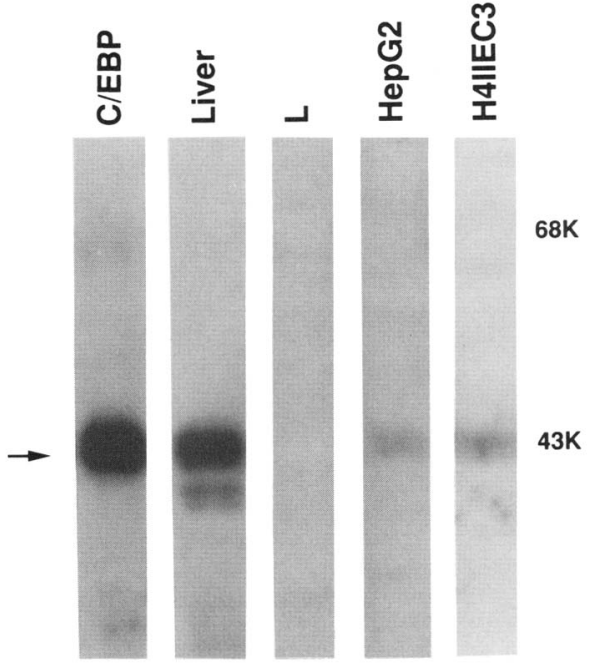

Figure 1. Western blot analysis of C/EBP abundance in cultured hepatoma-derived cell lines and in rat liver. Total cellular proteins from monolayer cells of rat liver nuclear proteins were analyzed by gel electrophoresis and Western blotting using a mixture of two antisera specific to C/EBP (Landschulz et al. 1988a; Birkenmeier et al. 1989|. Protein extracts corresponding to $1.5 \times 10^{6}$ cells or nuclei were loaded per lane. Samples are (from left to right) $25 \mathrm{ng}$ of bacterially expressed C/EBP (Landschulz et al. 1989|, rat liver nuclear proteins, mouse L cell proteins, HepG2 cell proteins, and H4IIEC 3 cell proteins. The position of full-length C/EBP is indicated by an arrow.

lines contain roughly one-twentieth the C/EBP content of adult rat liver cells $(\sim 5000$ molecules per cell). Extracts prepared from mouse $L$ cells showed no detectable C/EBP.

There are two reasons to believe that the lack of crossreacting material (CRM) in cultured mouse fibroblasts is caused by the absence of $\mathrm{C} / \mathrm{EBP}$ protein in this cell type. First, Northern blot assays of mouse L cell RNA have shown no evidence of C/EBP mRNA /S. McKnight, unpubl.). Second, previous experiments demonstrated cross-reactivity between both antibody reagents. These antibody reagents were generated using synthetic peptides corresponding to rat liver C/EBP (Landschulz et al. 1988a; Birkenmeier et al. 1989|, and the mouse form of the protein (Birkenmeier et al. 1989). The low level of CRM in H4IIEC3 cells also is likely to represent a bona fide measurement. Because H4IIEC3 cells were derived from a rat hepatoma, both antibody reagents should be capable of detecting the H4IIEC3 form of C/EBP fully. This cannot be concluded firmly in the case of HepG2 because we have yet to demonstrate cross-reactivity among our antibody reagents and human C/EBP.

To compare further the C/EBP content of rat liver and HepG2 cells, C/EBP DNA-binding activity, as assayed by DNase I footprinting on the hepatitis $B$ virus (HBV) enhancer, was compared using nuclear extracts prepared from these two sources (Fig. 2). To facilitate comparison, equivalent amounts of nucelar protein were used in the footprinting assays (see Materials and methods). Even after the addition of 120 units, the untransfected HepG2 cell extract exhibited only a very weak DNase I footprint 


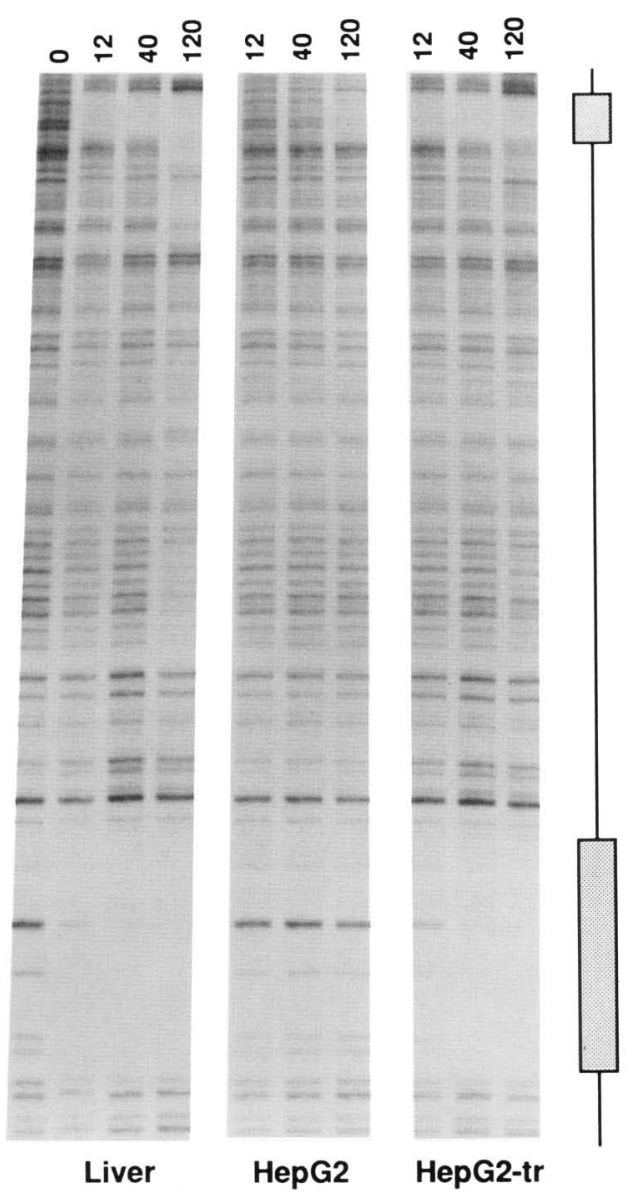

Figure 2. Footprint analysis of C/EBP DNA-binding activity in nuclear extracts from rat liver, HepG2 cells, and HepG2 cells transfected with an expression vector for native C/EBP (Hep G2-tr|. Heat-treated nuclear extracts from each souce were assayed by DNase I footprinting on the HBV enhancer. DNase I cleavage patterns were generated either in the absence of added protein $(0)$, or in the presence of 12,40 , or 120 units of each extract. One unit of extract was defined as $1 \mu \mathrm{g}$ of nuclear protein, determined prior to heat treatment. The locations of the two C/EBP-binding sites on the HBV enhancer are indicated by the stippled rectangles at the right side of the figure.

on the HBV enhancer (Fig. 2, middle panel). Under such conditions, evidence of protein-DNA interaction was limited to the stronger (upper) of the two C/EBP-binding sites. In contrast, addition of as little as 12 units of rat liver nuclear extract generated footprints on both the stronger (upper) and weaker (lower) C/EBP-binding sites (Fig. 2, left panel). These observations, consistent with the results of Western blot assays (see Fig. 1), indicated that C/EBP occurs at substantially less abundant levels in HepG2 cells than in hepatocytes of adult liver.

\section{Transient transfection facilitates expression of native and mutant forms of $C / E B P$ in cultured cells}

The vector used to express C/EBP in cultured cells, termed pMSV-C/EBP-wt, was constructed by fusing the complete open reading frame (ORF) of C/EBP down- stream from the murine sarcoma virus (MSV) long terminal repeat (LTR), and upstream from the polyadenylation signal of the herpes simplex virus $t k$ gene /see Materials and methods). To facilitate translation of C/EBP from the encoded mRNA, an oligonucleotide adaptor containing the consensus sequence that precedes eukaryotic translation initiation sites (Kozak 1987) was placed between the MSV-LTR and the translation initiation codon of C/EBP.

Before testing whether elevated levels of C/EBP might activate transcription from the albumin promoter, two additional expression vectors were constructed. One vector, termed pMSV-C/EBP-BR3, was prepared from a mutated copy of the C/EBP gene, encoding a protein incapable of binding DNA. The BR3 mutant contains amino acid substitutions at four positions within a highly basic region of the C/EBP polypeptide thought to correspond to the DNA contact surface (Landschulz et al. 1989). Another vector, termed pMSV-C/EBP-12V, was prepared from a mutated copy of the C/EBP gene, which encodes a protein incapable of either dimerization or DNA binding. The $12 \mathrm{~V}$ mutant contains amino acid substitutions at two positions within the 359 -aminoacid polypeptide, changing leucine residues 317 and 324 to valines (Landschulz et al. 1989).

$\mathrm{C} / \mathrm{EBP}$ expression from the three described expression vectors was examined by several different assays. The initial assay used to monitor C/EBP expression was DNA binding. The C/EBP expression vector pMSV C/EBP-wt was transfected into HepG2 cells as a calcium phosphate precipitate (see Materials and methods) and a nuclear extract was prepared. As depicted in Figure 2, transfected HepG2 cells acquire a heat-stable DNAbinding activity that interacts with the HBV enhancer at the same two locations as does the $\mathrm{C} / \mathrm{EBP}$ activity native to rat liver nuclei.

Second, when transfected into either HepG2 cells or mouse $\mathrm{L}$ cells, each expression vector led to the synthesis of protein that cross-reacted with C/EBP-specific antibodies. As demonstrated in the Western blot assays of Figure 3, polypeptide species generated from all three expression vectors, regardless of whether they were produced in HepG2 cells or mouse L cells, exhibited electrophoretic mobilities similar to that of bacterially produced C/EBP. Immunofluorescence staining assays showed further that each expression vector led to the appearance of nucleus-restricted CRM (Fig. 4). This assay also allowed rough quantitation of the number of productively transfected cells. Each expression vector led to the appearance of CRM in $\sim 1 \%$ of transfected HepG2 cells, and in $\sim 2 \%$ of transfected mouse L cells (data not shown).

\section{C/EBP expression in transfected cells activates transcription from the serum albumin promoter}

To test whether C/EBP might be capable of regulating transcription of the serum albumin gene, a chimeric albumin $-t k$ 'target' gene was cotransfected into cultured cells along with each of the three C/EBP expression vectors. The albumin $-t k$ chimera contained nucleotides 


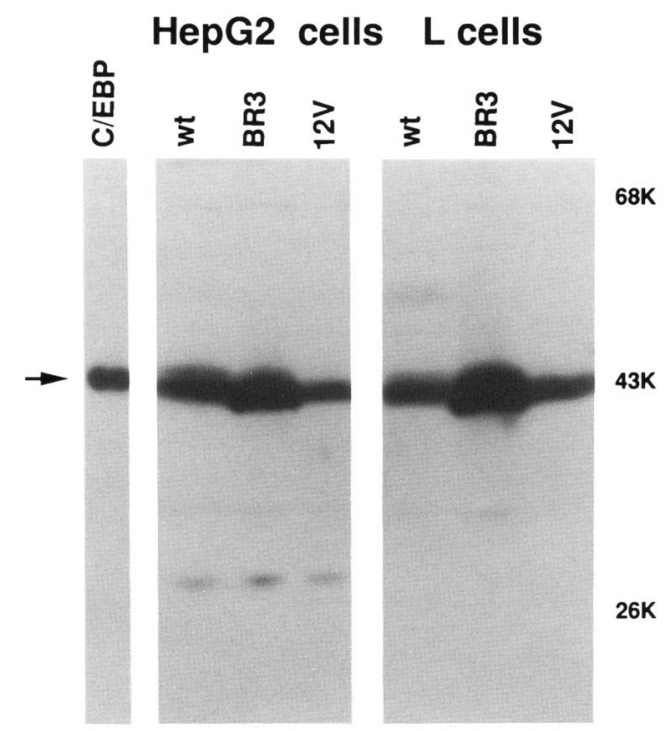

Figure 3. Western blot analysis of C/EBP expression in transiently transfected mammalian cells. Monolayer cultures of both HepG2 cells and mouse $L$ cells were transfected transiently with three different C/EBP expression vectors. One vector, pMSV-C/EBP-wt, encoded native C/EBP. The second vector, $\mathrm{pMSV}-\mathrm{C} / \mathrm{EBP}-\mathrm{BR} 3$, encoded a form of C/EBP that is incapable of binding DNA. The third vector, pMSV-C/EBP-12V, encoded a form of C/EBP that is incapable of both dimerization and DNA binding. Dishes of HepG2 cells $(100 \mathrm{~mm})$ were transfected with $40 \mu \mathrm{g}$ of expression vector; $100-\mathrm{mm}$ dishes of mouse $\mathrm{L}$ cells were transfected with $9 \mu \mathrm{g}$ of expression vector. Forty hours later, total cellular proteins were extracted and analyzed for C/EBP content by gel electrophoresis and Western blotting. The left-most lane was loaded with $25 \mathrm{ng}$ of bacterially expressed C/EBP. Remaining lanes were loaded with approximately $1 \times 10^{6} \mathrm{HepG} 2$ cell or $3 \times 10^{6} \mathrm{~L}$ cell equivalents of solubilized extract. The arrow indicates the position of fulllength C/EBP.

-787 to +8 , relative to the albumin mRNA cap site, fused to the 5' -untranslated region of the herpes simplex virus $t k$ gene. This potential target of $\mathrm{C} / \mathrm{EBP}$ regulation, termed pAT2, was constructed and kindly provided by M. DiPersio and K. Zaret. pAT2 DNA was transfected by the calcium phosphate method into HepG2 cells along with either salmon sperm DNA, pMSV-C/EBP-wt, pMSV-C/EBP-BR3, or pMSV-C/EBP-12V (see Materials and methods). Two days later, total cellular RNA was isolated and tested by primer extension for $t k$ mRNA. As shown in Figure 5 (left panel), cotransfection of pAT2 with pMSV-C/EBP-wt led to the appearance of substantial levels of an RNA species detected by the $t k$ primer. The length of the primer extension product coincided with that expected from transcription initiation at the native albumin mRNA cap site /see Materials and methods). Considerably less of this primer extension product was observed if pAT2 was cotransfected into HepG2 cells with salmon sperm DNA. Similarly low amounts of the chimeric albumin-tk mRNA were observed when pAT2 was cotransfected with either of the expression vectors that lead to the synthesis of defective C/EBP (pMSV-C/EBP-BR3 or pMSV-C/EBP-12V).
Analogous transient cotransfection experiments were carried out using cultured fibroblasts (mouse L cells). In the latter case, DNA was introduced by the DEAE-dextran/DMSO shock method (see Materials and methods). As with HepG2 cells, the highest level of PAT2 expression was observed in cells that had been cotransfeced with pMSV-C/EBP-wt. However, in the case of mouse $\mathrm{L}$ cells, the activating capacity of pMSV-C/EBP-wt, relative to salmon sperm DNA or either of the expression vectors that encode defective $\mathrm{C} / \mathrm{EBP}$, appeared to be more modest than in HepG2 cells (Fig. 5, right panel).

\section{Activation of the albumin promoter depends on an intact $C / E B P$-binding site}

A series of $5^{\prime}$-deletion mutants was prepared to determine whether the albumin promoter might harbor cisregulatory DNA sequences critical for trans-activation by pMSV-C/EBP-wt. In addition to pAT2, which contained $787 \mathrm{bp}$ of DNA upstream from the albumin mRNA cap site, deletions terminating at positions $-551,-395,-217$, and -80 were tested by transient transfection. Each deletion mutant was cotransfected into HepG 2 cells along with either salmon sperm DNA or pMSV-C/EBP-wt. Two days later, RNA was harvested and examined by primer extension for $t k$ mRNA. When
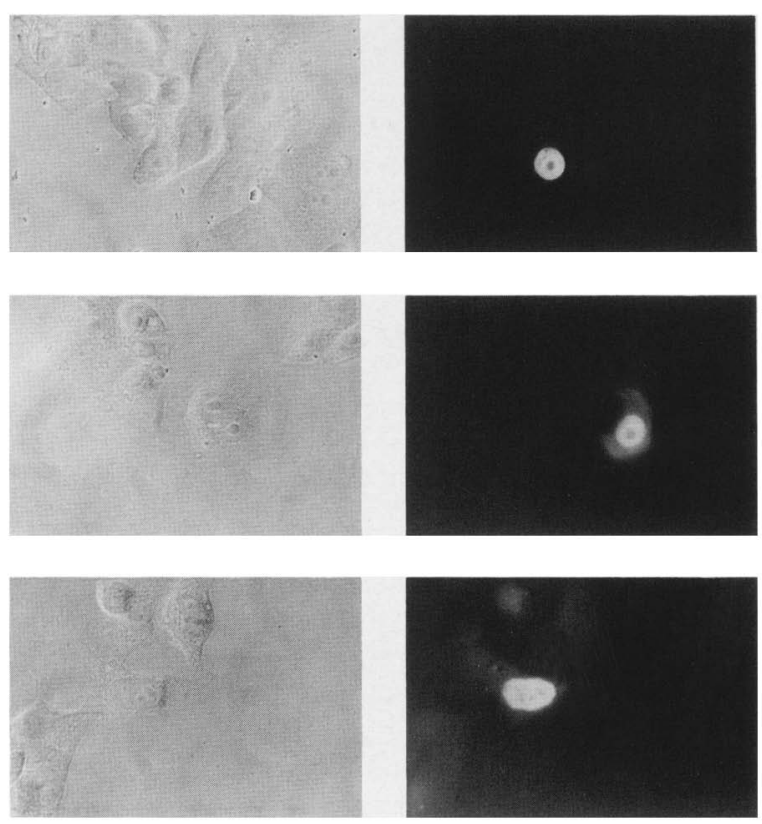

Figure 4. Immunofluorescence analysis of C/EBP expression in transiently transfected mammalian cells. HepG2 cells were transfected with $40 \mu \mathrm{g}$ of either pMSV-C/EBP-wt, pMSV-C/ EBP-BR3, or pMSV-C/EBP-12V. The cells were split onto coverslips $16 \mathrm{hr}$ post-transfection. Cells were fixed $40 \mathrm{hr}$ after initial exposure to DNA and processed for immunofluorescence and phase microscopy as described in Materials and methods. Phase contrast (left) and indirect immunofluorescent $($ right $) \mathrm{mi}$ crographs are shown for cells transfected with each expression vector. (Top) Cells transfected with pMSV-C/EBP-wt, (middle) cells transfected with pMSV-C/EBP-BR3, (bottom) cells transfected with pMSV-C/EBP-12V are shown. 


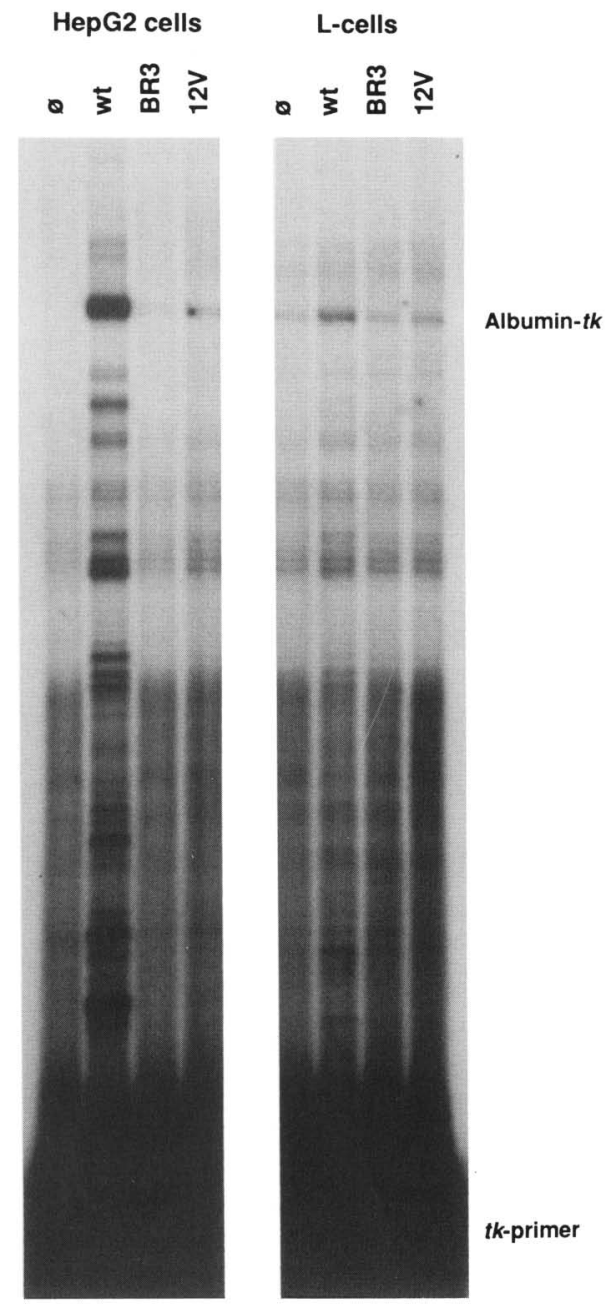

Figure 5. Transient activation of the promoter of the mouse serum albumin gene by C/EBP. HepG 2 cells were transfected with $10 \mu \mathrm{g}$ of pAT2 and $40 \mu \mathrm{g}$ of either sonicated salmon sperm DNA (0), pMSV-C/EBP-wt (wt), pMSV-C/EBP-BR3 (BR3), or pMSV-C/EBP-12V (12V). Mouse L cells were transfected with 3 $\mu \mathrm{g}$ of pAT2 and $9 \mu \mathrm{g}$ of either sonicated salmon sperm DNA or each of the same three expression vectors. Forty hours after transfection, cells were harvested, RNA was isolated, and $t k$ mRNA was detected by primer extension analysis. The positions of the major extension product from the albumin-tk target and the $t k$ primer are indicated.

expression was examined in the absence of pMSV-C/ EBP-wt, the level of expression of all constructs was low (Fig. 6). However, close inspection of autoradiographic exposures did reveal extension products that map at a position corresponding to the transcripts that had initiated at the authentic albumin mRNA cap site. As shown in Figure 6 (lower panel), this low level of accurate transcription was reduced to an undetectable level upon deletion from residue -217 to residue -80 . When the same series of deletion mutants was tested in the presence of cotransfected pMSV-C/EBP-wt, a substantially higher level of albumin promoter activity was maintained so long as at least 217 bp upstream from the albumin mRNA cap site remained intact.
It is known that the albumin promoter contains an avid C/EBP-binding site in the region between residues -217 and -80 /Cereghini et al. 1987; Lichtsteiner et al. 1987). This C/EBP-binding site, variously termed the D site or distal element I (DEI), was mutated by the introduction of seven nucleotide substitutions in the background of pAT2 (see Materials and methods). As shown in Figure 6, this cluster of base substitution mutations in DEI (termed $\triangle \mathrm{DEI}$ ) was as deleterious as the -80 deletion, whether assayed in the presence or absence of cotransfected pMSV-C/EBP-wt.

It was anticipated that the cluster of bp substitutions present in $\triangle \mathrm{DEI}$ would inactivate the C/EBP-binding site. This assumption was tested by DNase I footprinting using C/EBP prepared from rat liver nuclei. As shown in Figure 7 , the $\triangle D E I$ mutation did block the in vitro binding of $\mathrm{C} / \mathrm{EBP}$ to the albumin promoter.

\section{Discussion}

The results presented in this report show that C/EBP, when expressed in transiently transfected mammalian cells, can activate transcription from the serum albumin promoter. There are several reasons to suspect that the observed activation may involve direct interaction between $\mathrm{C} / \mathrm{EBP}$ and the albumin promoter. First, activation was dependent on the ability of $\mathrm{C} / \mathrm{EBP}$ to bind DNA. The two expression vectors that encoded forms of C/EBP known to be incapable of sequence-specific interaction with DNA failed to trans-activate the albumin promoter. Second, activation was dependent on the integrity of DEI, the strong C/EBP-binding site that occurs within the albumin promoter.

Expression of pAT2, the albumin-tk reporter gene used in transient transfection assays, was nearly unde-

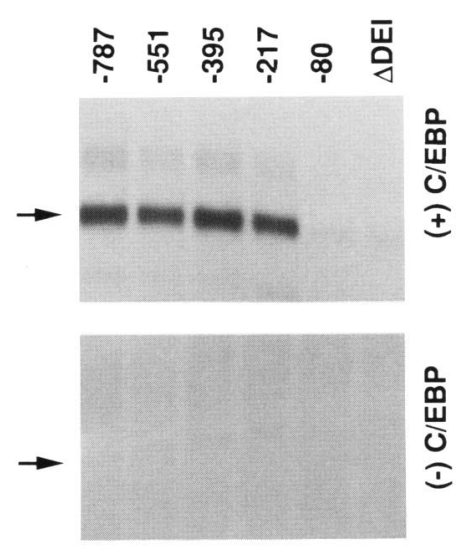

Figure 6. Analysis of albumin DNA sequence elements necessary for trans-activation by C/EBP. Dishes of HepG2 cells $\{100$ $\mathrm{mm}$ ) were transfected with $10 \mu \mathrm{g}$ of either pAT2, one of four deletion derivatives, or pAT2/ $\triangle \mathrm{DEI}$, along with either $40 \mu \mathrm{g}$ of salmon sperm DNA (bottom, - C/EBP) or $40 \mu \mathrm{g}$ of pMSV-C/ EBP-wt (top + C/EBP). Cells were harvested 40 hr post-transfection, and RNA was isolated and assayed for tk mRNA by primer extension. The positions of the major extension products are indicated (arrows). The autoradiograph (bottom) was exposed four times longer than that shown at the top. 


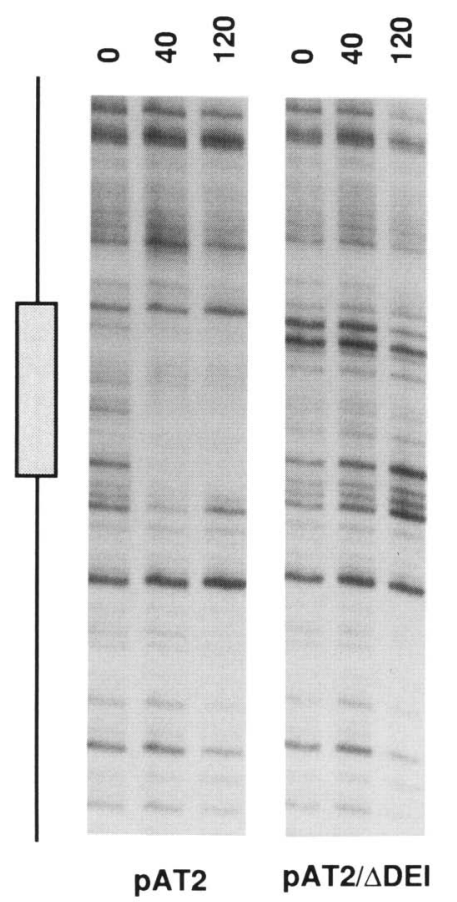

Figure 7. DNA-binding assays of $\mathrm{C} / \mathrm{EBP}$ to the native albumin promoter and the $\triangle D E I$ derivative. Plasmid DNA corresponding to pAT2 and pAT2/DDEI was ${ }^{32} \mathrm{P}$ labeled approximately $120 \mathrm{bp}$ downstream from the DEI site. DNA was then used in DNase I footprinting assays using $\mathrm{C} / \mathrm{EBP}$ prepared from rat liver nuclei. DNase I cleavage patterns were generated in the presence of either 0,40 , or $120 \mathrm{U}$ (see Fig. 1) of extract. The position of the DEI element is designated by the stippled bar at the left side of the figure.

tectable in the absence of cotransfected pMSV-C/EBP$\mathrm{wt}$. The low level of expression observed in the absence of pMSV-C/EBP-wt disappeared when the DEI site was eliminated from the albumin promoter. The low level of DEI-dependent transcription observed in HepG2 cells might be a result of the low level of endogenous C/EBP present in these cells (Figs. 1 and 2). Alternatively, another protein $\mathrm{D}$-site binding protein (DBP), has been observed to bind to the DEI site (Maire et al. 1989). It is possible that $\mathrm{DBP}$, rather than $\mathrm{C} / \mathrm{EBP}$, activates the albumin promoter in HepG2 cells through DEI. Analogous experiments to those presented herein using a DBP expression vector might help clarify this issue.

Ectopic expression of C/EBP in mouse $L$ cells also caused an increase in expression from pAT2. Such activation was not observed with either of the expression vectors that encoded defective forms of the C/EBP polypeptide. The degree of C/EBP-mediated activation observed in mouse $\mathrm{L}$ cells was substantially less than that observed in HepG2 cells, although basal levels of expression from pAT2 were higher in mouse L cells. Comparison between the two cell types are attended by many potential complications, including the use of different transfection techniques. Because we succeeded in using mouse L cells to study trans-activation in three other systems (Eisenberg et al. 1985; Graves et al. 1985; Triezenberg et al. 1988a,b), we suspect that differences in transfection procedures may not account for the substantial difference in C/EBP-mediated trans-activation relative to HepG2 cells. Given these obvious caveats, what can be made of the observation that the degree of activation of the albumin promoter in HepG2 cells was more than an order of magnitude greater than in mouse $\mathrm{L}$ cells? One potential interpretation is that hepatomaspecific expression of the albumin promoter in the presence of excess C/EBP makes use of other regulatory proteins that do not occur in mouse L cells. Extensive studies on protein factors that bind to the albumin promoter (Cereghini et al. 1988; Maire et al. 1989) revealed the importance of a hepatocyte-specific DNA-binding protein (HNF1) (Courtois et al. 1987). Perhaps C/EBP synergizes with HNF1, leading to a more potent level of activation than would be observed in cells that lack HNF1. Alternatively, it is possible that nonhepatic cells contain an inhibitor of C/EBP-mediated gene activation. Observations consistent with this second model have emerged from somatic cell fusions between hepatoma cells and microcells derived from mouse $L$ cells (Petit et al. 1986). One potential means of distinguishing between these alternatives would involve studies of the additional cis-regulatory sequences required for the elevated level of C/EBP-mediated activation observed in HepG2 cells. For example, must the HNFl-binding site, located between residues -62 and -32 within the albumin promoter, remain intact to retain higher levels of activation in hepatocytes than in fibroblasts? Experiments of this nature are in progress.

Perhaps the most enigmatic observation to have emerged from these studies concerns the surprisingly low levels of $C / E B P$ present in cultured hepatoma cells. Both HepG2 and H4IIEC3 cells, whether assayed by Western blotting or direct DNA binding, contain at least an order of magnitude less C/EBP than hepatocytes of adult liver. It has now become reasonably clear that $\mathrm{C} / \mathrm{EBP}$ is capable of activating genes that are expressed in differentiated hepatocytes. We demonstrated C/EBPmediated activation of the albumin gene, and Lane and colleagues (Christy et al. 1989) demonstrated similar activation of the gene encoding stearoyl-CoA desaturase (SCD). C/EBP also activates the SCD gene in transiently transfected 3T3-Ll cells (Christy et al. 1989), consistent with earlier predictions that C/EBP might play a regulatory role in the conversion of proliferative adipoblasts into fully differentiated adipocytes (Birkenmeier et al. 1989). We speculate that C/EBP may function, along with other regulatory proteins, to effect and/or maintain the differentiated state. One long recognized property of the differentiated state is the markedly decreased frequency of cell division. Perhaps, in addition to activating genes that encode specialized proteins necessary for acquisition of the differentiated state, C/EBP also plays a role in preventing cell division. If so, its removal or diminution may be a necessary step in the cascade of events that leads to cellular proliferation typical of regenerating or neoplastic liver tissue. 


\section{Materials and methods \\ Cell culture and transient transfection}

Monolayers of human hepatoma (HepG2) cells (Aden et al. 1979) and rat hepatoma (H4IIEC3) cells were maintained in a 1:1 mixture of Dulbecco's modified Eagle's medium (DMEM) and Ham's F12 medium supplemented with $10 \%$ fetal calf serum and $10 \mu \mathrm{g} / \mathrm{ml}$ of insulin. Mouse L cells (Kit et al. 1963) were maintained as monolayers in DMEM supplemented with $10 \%$ fetal calf serum.

Transfection of hepatoma cells was carried out according to the calcium phosphate method (Graham et al. 1973). Calcium phosphate precipitates were removed $16 \mathrm{hr}$ after their addition. Then cells were washed with $6 \mathrm{ml}$ of phosphate-buffered saline (PBS) and fed with $10 \mathrm{ml}$ of culture medium. Transfection of $\mathrm{L}$ cells was carried out according to the DEAE-dextran method (Lopata et al. 1984). Cells were harvested $40 \mathrm{hr}$ after initial exposure to DNA. One-third of each RNA sample was used in each extension reaction.

RNA preparation and primer extension analysis were carried out as described (Eisenberg et al. 1985). The primer used was a synthetic oligonucleotide that hybridizes between residues +56 and +80 relative to the $t k$ mRNA cap site. The major primer extension product diagnostic of expression from pAT2 and its derivatives was sized relative to molecular weight markers prepared by digesting pBR322 plasmid DNA with MspI. The major extension product was $\sim 102-106$ bp in length, corresponding well with the 104-bp distance from the albumin mRNA cap site to the $3^{\prime}$ end of the $t k$ primer annealing site in pAT2.

Immunofluorescence and phase microscopy was conducted using cells grown on acid-etched coverslips. Cells were fixed with $1.6 \%$ paraformaldehyde in PBS. Indirect immunofluorescence was carried out as described (Friedman et al. 1988) using a polyclonal rabbit antisera directed against a 14-residue synthetic peptide derived from a region immediately amino terminal to the C/EBP DNA-binding domain (Landschulz et al. 1988a).

\section{Recombinant plasmids}

The HBV enhancer (Jameel and Siddiqui 1986; Shaul and BenLevy 1987) DNA fragment used for DNase I footprinting was prepared as described (Landschulz et al. 1988a). The albumin promoter-containing plasmid, pAT2, was kindly provided by $\mathrm{K}$. Zaret (M. DiPersio and K. Zaret, unpubl.). It contained, in pUC18, sequences -787 to +8 of the mouse albumin gene linked via a 19 -bp polylinker to the HSV-1 $t k$ gene, beginning at base pair +4 relative to the mRNA cap site. A 5 ' deletion series was created by first digesting pAT2 with EcoRI, which linearizes the plasmid at a point 16 -bp upstream from the albumin promoter segment. Then the resulting DNA was digested for various time periods with ExoIII (New England Biolabs). Pooled, ExolII-digested DNA then was digested with mung bean nuclease (New England Biolabs), ligated to EcoRI linker (Collaborative Research), and codigested with EcoRI and HindIII. Deleted fragments were sized on a $1.2 \%$ agarose gel, recovered, and inserted into pUC18 plasmid that had been cut with EcoRI and HindIII. Deletion end points were determined by DNA sequencing (Maxam and Gilbert 1980).

Clustered point mutations were introduced at the DEI site of pAT2 by oligonucleotide-directed mutagenesis (Smith 1985) using a 41-residue synthetic oligonucleotide 15'-GGC AAA GAT GGT ATG AGA AGC TTC TGG GGT AGG AAC CAA TG-3'). This procedure resulted in mutation of base pairs -99 ,
-100 , and -102 to -106 of the albumin promoter and insertion of a HindIII site. Accuracy of the mutagenesis was determined by chemical DNA sequencing and by HindIII digestion. The resulting plasmid was designated pAT2/DDEI.

An expression vector that encodes native $C / E B P$, termed pMSV-C/EBP-wt, was created in three steps. First, two synthetic oligonucleotides $\left(5^{\prime}\right.$-GGA TCC ATG GTG GCG CG-3' and 5'-AAT TCG CGC CAC CAT GGA TCC-3') were annealed, and inserted into the polylinker of Bluescript (Stratagene) (after this vector was digested with EcoRI and EcoRV) to create a derivative termed pKRBS. The synthetic insert in pKRBS contains the consensus sequence for a eukaryotic translation initiation site (Kozak 1987) overlapping an Ncol restriction site. The C/EBP gene contains an Ncol site at the initiating ATG and a HindIII site in the 3 '-untranslated region (Landschulz et al. 1988a). Therefore, an NcoI-HindIII fragment containing the entire ORF of C/EBP was inserted into pKRBS after NcoI-HindIII digestion to create pKR-C/EBP. Finally, a fragment of pKR-C/EBP containing the translational adaptor, the $\mathrm{C} / \mathrm{EBP} \mathrm{ORF}$, and $380 \mathrm{bp}$ of $3^{\prime}$-untranslated sequences was inserted into a vector containing the MSV-LTR /Graves et al. 1985 and the polyadenylation signal of the HSV $t k$ gene (McKnight 1980) as follows: ptk/ $\Delta 5^{\prime}-109$ (McKnight et al. 1981) was digested first with SmaI. PstI linkers (Collaborative Research) then were ligated and the resulting DNA mix was digested with PstI and HindIII to liberate a 390-bp fragment containing the $t k$ polyadenylation sequences. This fragment was ligated to the larger DNA fragment obtained after digestion of pKR-C/EBP with PstI and HindIII, thereby removing a portion of the C/EBP $3^{\prime}$-untranslated region and inserting the $t k$ fragment. This construct, pKR-C/EBPtk then was digested with BamHI and HindIII and the fragment containing the translational adaptor, C/EBP sequences, and $t k$ sequences, was ligated into a vector created by digesting pMSVP16 (Triezenberg et al. 1988a) with BamHI and HindIII, removing VP16 and $t k$ sequences, but leaving the $430-b p$ MSV-ITR and the pEMBL 19 vector sequences.

Expression vectors that encode mutant forms of C/EBP, pMSV-C/EBP-BR3, and pMSV-C/EBP-12V, were created by digesting pMSV-C/EBP-wt with MluI and NcoI to remove a DNA fragment encoding the carboxy-terminal protein of C/EBP. Corresponding MluI-NcoI fragments from plasmids designed to express the C/EBP-BR3 and C/EBP-12V mutant polypeptides in bacteria (Landschulz et al. 1989) were ligated in its place.

\section{Protein extracts}

Total cellular protein extracts were prepared from monolayer cells for Western blot analysis as described previously (Triezenberg et al. 1988a). Cell number was determined by trypsinizing duplicate monolayers and counting cells using a hemocytometer. Rat liver nuclei used for Westem blot analysis were prepared as described (Gorski et al. 1986). After resuspension in nuclear lysis buffer, nuclei were counted using a hemocytometer, then lysed by the addition of $1 \times$ protein gel sample buffer (Laemmli 1970) and vigorous sonication.

For electrophoretic separation of proteins, each sample was heated to $100^{\circ} \mathrm{C}$ for $3 \mathrm{~min}$ in sample buffer and loaded onto a $10 \%$ polyacylamide-SDS gel (Laemmli 1970). After electrophoresis, proteins were transferred to nitrocellulose (Towbin et al. 1979) and probed using a mixture of two C/EBP-specific antisera (Landschulz et al. 1988a; Birkenmeier et al. 1989). Antigen-antibody complexes were detected using ${ }^{125}$ I coupled to protein A (Amersham) and visualized by autoradiography.

Extracts from monolayer cells were prepared for DNase I footprinting by the methods of Dignam et al. (1983) as modified 
by Lee et al. (1988). Rat liver nuclear extracts for footprinting were obtained as described (Gorski et al. 1986). Protein concentrations of nuclear extracts were determined by the method of Bradford using bovine serum albumin as a standard (Bradford 1976) C/EBP was purified partially by subjecting the extracts to heat treatment at $80^{\circ} \mathrm{C}$ for $5 \mathrm{~min}$ (Johnson et al. 1987). Insoluble debris was removed by centrifugation, and DNase I footprinting was carried out using soluble material as described (Graves et al. 1986).

\section{Acknowledgments}

We thank Bob Kingsbury for extensive technical assistance, Jon Shuman and Peter Johnson for providing rat liver nuclear extract, Barbara Graves for teaching us how to culture and transfect HepG2 cells, Ken Zaret for providing pAT2, Christine Norman for clerical assistance, and our many colleagues at the Carnegie Embryology Department for criticism and encouragement. A.D.F. was supported by a Physician Scientist Award from the National Institutes of Health (NIH); W.H.L. is a Medical Scientist Scholar of the Life and Health Insurance Medical Research Fund; and S.L.M. was provided support from the NIH, the Howard Hughes Medical Research Institute, and the Carnegie Institution of Washington.

\section{References}

Aden, D.P., A. Fogel, S. Plotkin, I. Damjanov, and B.B. Knowles. 1979. Controlled synthesis of HBsAg in a differentiated human liver carcinoma-derived cell line. Nature 282: 615618.

Babiss, L.E., R.S. Herbst, A.L. Bennett, and J.E. Darnell, Jr. 1987. Factors that interact with the rat albumin promoter are present both in hepatocytes and other cell types. Genes Dev. 1: 256-267.

Birkenmeier, E.H., B. Gwynn, S. Howard, J. Jerry, J.I. Gordon, W.H. Landschulz, and S.L. McKnight. 1989. Tissue-specific expression, developmental regulation and genetic mapping of the gene encoding C/EBP. Genes Dev. 3: 1146-1156.

Bradford, M.M. 1976. A rapid and sensitive method for the quantitation of microgram quantities of protein utilizing the principle of protein-dye binding. Anal. Biochem. 72: 248254.

Cereghini, S., M. Raymondjean, A.G. Carranca, P. Herbomel, and M. Yaniv. 1987. Factors involved in control of tissuespecific expression of albumin gene. Cell 50: 627-638.

Cereghini, S., M. Blumenfeld, and M. Yaniv. 1988. A liver-specific factor essential for albumin transcription differs between differentiated and dedifferentiated rat hepatoma cells. Genes Dev. 2: 957-974.

Christy, R.J., V.W. Yang, J.M. Ntambi, D.E. Geiman, W.H Landschulz, A.D. Friedman, Y. Nakabeppu, T.J. Kelly, and M.D. Lane. 1989. Differentiation induced gene expression in 3T3-L1 preadipocytes: CCAAT/enhancer binding protein interacts with and activates the promoters of two adipocytespecific genes. Genes Dev. 3: 1322-1334.

Costa, R.H., D.R. Grayson, K.G. Xanthopoulos, and J.E. Darnell, Jr. 1988. A liver-specific DNA-binding protein recognizes multiple nucleotide sites in regulatory regions of transthyretin, $\alpha$-1-antitrypsin, albumin, and SV40 genes. Proc. Natl. Acad. Sci. 85: 3840-3844.

Courtois, G., J.G. Morgan, L.A. Campbell, G. Fourel, and G.R. Crabtree. 1987. Interaction of a liver-specific nuclear factor with the fibrinogen and $\alpha$-1-antitrypsin promoters. Science 238: $688-692$.

Dignam, J.D., R.M. Lebovitz, and R.G. Roeder. 1983. Accurate transcription initiation by RNA polymerase II in a soluble extract from isolated mammalian nuclei. Nucleic Acid. Res. 11: $1475-1489$.

Eisenberg, S.P., D.M. Coen, and S.L. McKnight. 1985. Promoter domains required for expression of plasmid-borne copies of the herpes simplex virus thymidine kinase gene in virus-infected mouse fibroblasts and microinjected frog oocytes. Mol. Cell. Biol. 5: 1940-1947.

Friedman, A.D., S.J. Triezenberg, and S.L. McKnight. 1988. Expression of a truncated viral trans-activator selectively impedes lytic infection by its cognate virus. Nature 335: $452-$ 454

Gorski, K., M. Carneiro, and U. Schibler. 1986. Tissue-specific in vitro transcription from the mouse albumin promoter. Cell 47: 767-776.

Graham, F.L. and A.J. Van der Eb. 1973. A new technique for the assay of infectivity of human adenovirus 5 DNA. Virology 52: 456-457.

Graves, B.J., R.N. Eisenman, and S.L. McKnight. 1985. Delineation of transcriptional control signals within the Moloney murine sarcoma virus long terminal repeat. Mol. Cell. Biol. 5: $1948-1958$

Graves, B., P.F. Johnson, and S.L. McKnight. 1986. Homologous recognition of a promoter domain common to the MSV LTR and the HSV $t k$ gene. Cell 44: 565-576.

Heard, J.M., P. Herbomel, M.O. Ott, A. Mottura-Rollier, M. Weiss, and M. Yaniv. 1987. Determinants of rat albumin promoter tissue specificity analyzed by an improved transient expression system. Mol. Cell. Biol. 7: 2425-2434.

Jameel, S. and A. Siddiqui. 1986. The human hepatitis B virus enhancer requires trans-acting cellular factor(s) for activity. Mol. Cell Biol. 6: 710-715.

Johnson, P.F., W.H. Landschulz, B.J. Graves, and S.L. McKnight. 1987. Identification of a rat liver nuclear protein that binds to the enhancer core element of three animal viruses. Genes Dev. 1: 133-146.

Kit, S., D.R. Dubbs, L.J. Piekarski, and T.C. Hsu. 1963. Deletion of thymidine kinase activity from $\mathrm{L}$ cells resistant to bromodeoxyuridine. Exper. Cell Res. 31: 297-312.

Kozak, M. 1987. At least six nucleotides preceding the AUG initiator codon enhance translation in mammalian cells. $I$. Mol. Biol. 196: 947-950.

Laemmli, U.D. 1970. Cleavage of structural proteins during the assembly of the head of bacteriophage T4. Nature 227: 680685.

Landschulz, W.H., P.F. Johnson, E.Y. Adashi, B.J. Graves, and S.L. McKnight. 1988a. Isolation of a recombinant copy of the gene encoding C/EBP. Genes Dev. 2: 786-800.

Landschulz, W.H., P.F. Johnson, and S.L. McKnight. 1988b. The leucine zipper: A hypothetical structure common to a new class of DNA-binding proteins. Science 240: 1759-1764.

Landschulz, W.H., P.F. Johnson, and S.L. McKnight. 1989. The DNA-binding domain of the rat liver nuclear protein C/EBP is bipartite. Science 243: 1681-1688.

Lee, K.A.W., A. Bindereif, and M.R. Green. 1988. A small-scale procedure for preparation of nuclear extracts that support efficient transcription and pre-mRNA splicing. Gene Anal. Technol. 5: 22-31.

Lichtsteiner, S., J. Wuarin, and U. Schibler. 1987. The interplay of DNA-binding proteins on the promoter of the mouse albumin gene. Cell 51: 963-973.

Lopata, M.A., D.W. Cleveland, and B. Sollner-Webb. 1984. High level expression of a chloramphenicol acetyl transferase gene by DEAE-dextran mediated DNA transfection coupled with a dimethyl sulfoxide or glycerol shock treatment. $\mathrm{Nu}$ cleic Acids Res. 12: 5707-5717. 
Maire, P., J. Wuarin, and U. Schibler. 1989. The role of cisacting promoter elements in tissue-specific albumin gene expression. Science 244: 343-346.

Maxam, A. and W. Gilbert. 1980. Sequencing end-labeled DNA with base-specific chemical cleavages. Methods Enzymol. 65: 499-560.

McKnight, S.L. 1980. The nucleotide sequence and transcript map of the herpes simplex virus thymidine kinase gene. $\mathrm{Nu}$ cleic Acids Res. 24: 5949-5964.

McKnight, S.L., E.R. Gavis, R. Kingsbury, and R. Axel. 1981. Analysis of transcriptional regulatory signals of the HSV thymidine kinase gene: Identification of an upstream control region. Cell 25: 385-398.

Petit, C., J. Levilliers, M.-O. Ott, and M.C. Weiss. 1986. Tissuespecific expression of the rat albumin gene: genetic control of its extinction in microcell hybrids. Proc. Natl. Acad. Sci. 83: $2561-2565$

Reuber, M.S. 1961. A transplantable bile-secreting hepatocellular carcinoma cell in the rat. $I$. Natl. Cancer Inst. 26: $891-899$.

Shaul, Y. and R. Ben-Levy. 1987. Multiple nuclear proteins in liver cells are bound to hepatitis $B$ virus enhancer element and its upstream sequences. EMBO J. 6: 1913-1920.

Smith, M. 1985. In vitro mutagenesis. Annu. Rev. Genet. 19: 423-463.

McKnight, S.L. 1980. The nucleotide sequence and transcript map of the herpes simplex virus thymidine kinase gene. $\mathrm{Nu}$ cleic Acids Res. 24: 5949-5964.

McKnight, S.L., E.R. Gavis, R. Kingsbury, and R. Axel. 1981. Analysis of transcriptional regulatory signals of the HSV thymidine kinase gene: Identification of an upstream control region. Cell 25: 385-398.

Petit, C., J. Levilliers, M.-O. Ott, and M.C. Weiss. 1986. Tissuespecific expression of the rat albumin gene: genetic control of its extinction in microcell hybrids. Proc. Natl. Acad. Sci. 83: $2561-2565$.

Reuber, M.S. 1961. A transplantable bile-secreting hepatocellular carcinoma cell in the rat. I. Natl. Cancer Inst. 26: $891-899$.

Shaul, Y. and R. Ben-Levy. 1987. Multiple nuclear proteins in liver cells are bound to hepatitis $B$ virus enhancer element and its upstream sequences. EMBO /. 6: 1913-1920.

Smith, M. 1985. In vitro mutagenesis. Annu. Rev. Genet. 19: $423-463$.

Towbin, H., T. Staehelin, and J. Gerdon. 1979. Electrophoretic transfer of proteins from polyacylamide gels to nitrocellulose sheets: procedure and some applications. Proc. Natl. Acad. Sci. 76: 4350-4354.

Triezenberg, S.J., R.C. Kingsbury, and S.L. McKnight. 1988a. Functional dissection of VP16, the trans-activator of herpes simplex virus immediate early gene expression. Genes Dev. 2: $718-729$.

Triezenberg, S.J., K.L. Lamarco, and S.L. McKnight. 1988b. Evidence of DNA: protein interactions that mediate HSV-1 immediate early gene activation by VP16. Genes Dev. 2: 730742. 


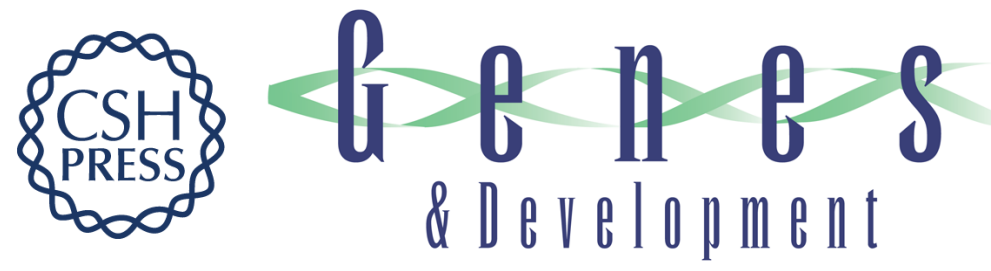

\section{CCAAT/enhancer binding protein activates the promoter of the serum albumin gene in cultured hepatoma cells.}

A D Friedman, W H Landschulz and S L McKnight

Genes Dev. 1989, 3:

Access the most recent version at doi:10.1101/gad.3.9.1314

References This article cites 45 articles, 19 of which can be accessed free at:

http://genesdev.cshlp.org/content/3/9/1314.full.html\#ref-list-1

License

Email Alerting

Service

Receive free email alerts when new articles cite this article - sign up in the box at the top right corner of the article or click here.

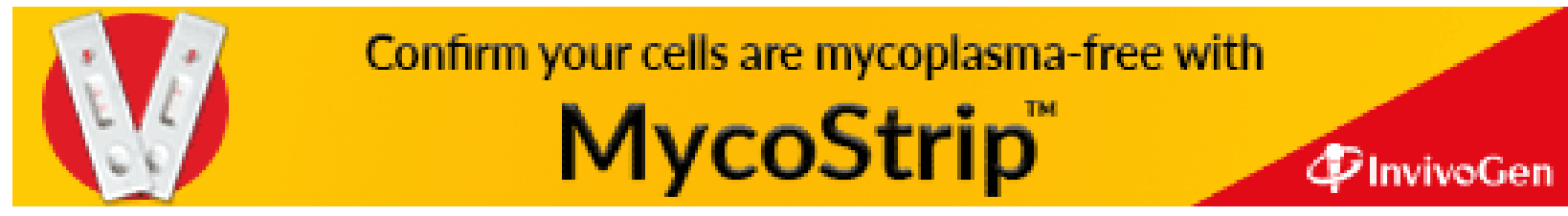

